\title{
Game Features of Cognitive Training
}

\author{
Michael P. Craven \\ NIHR MindTech Healthcare Technology Co-operative \\ \& Bioengineering research group, University of \\ Nottingham, Faculty of Engineering \\ Nottingham, UK \\ michael.craven@nottingham.ac.uk
}

\author{
Carlo Fabricatore \\ School of Computing and Engineering \\ University of Huddersfield \\ Huddersfield, UK \\ c.fabricatore@hud.ac.uk
}

\begin{abstract}
Cognitive training aimed at older adults is introduced and the issues of engagement and adhesion are discussed. Two examples of 'brain training' games are analysed, one with a health (non-leisure) focus that is currently being deployed in a clinical trial (Protect Brain Training Study) and the other focussed on leisure that is available on a consumer games console (Big Brain Academy for Wii). Both are based on a set of mini-games which are aimed at training and/or testing reasoning, planning, concentration, identification, maths, visuospatial and memory skills. The game mechanics of the two examples are analysed in detail, summarised and discussed. The paper concludes with an outline of the future research direction.
\end{abstract}

Keywords - cognitive training, healthy older adult, dementia, cognitive health intervention, serious game, content analysis

\section{INTRODUCTION}

Evidence of benefit from the use of cognitive training by healthy older adults is increasing. A recent large randomised controlled trial showed significant improvements in the primary outcome of instrumental activities of daily living (IADL) in adults over 60 and benefit in adults over 50 on an independent cognitive test battery, from playing online games several times a week [1].

Although the efficacy of computer-based cognitive training in people with cognitive impairment from brain diseases such as dementia remains unproven, the above trial also showed benefits for a sub-group of adults with low baseline reasoning score. Furthermore, there is evidence of benefits from cognitive stimulation during work and leisure, computer-based stimulation and from computer use in general for people with cognitive impairment $[2,3]$.

An overview of some games aimed at cognitive health can be found in the literature including a number of commercial 'dementia-related serious games' reviewed by McCallum and Boletsis [4]. Robert et al. have produced some initial recommendations for games for people with cognitive impairments and frailty from analysis of user elicitation workshops [5] and Cota et al. have elicited opinion on motivations of older adults to play mini-games [6].

The aim of this paper is to delve more deeply into the mechanics of cognitive training games. Given some contrasting evidence from clinical studies on dose-response effects of game-based cognitive training and concern about drop-out in long-term use [1,7], it would be useful to identify

The research reported in this paper was conducted by the NIHR MindTech Healthcare Technology Co-operative. This work has been funded by the National Institute for Health Research. The views represented are the views of the authors alone and do not necessarily represent the views of the Department of Health in England, NHS, or the National Institute for Health Research. and investigate game elements essential to the implementation of cognitive training and those which may trigger, maintain and/or increase engagement without overburdening the user. For this purpose, we outline player-centred perspectives that are key to identifying and analysing elements to foster engagement and facilitate purposeful playing of serious games. We then present a comparative case study involving a non-leisure cognitive training game (the Protect Brain Training Study [8]) and a leisure example (Big Brain Academy for Wii[9]).

\section{ENGAGEMENT AND ADHESION IN GAMES}

Sustained player engagement is paramount to the success of any digital game and, consequently, to the efficacy and sustainability of health programmes relying on voluntary purposeful game playing. Engagement can be broadly regarded as a multi-dimensional phenomenon involving a state of persistent and positive involvement in activity, and defined by the interplay of cognition, affect and behaviour of the engaged subject $[10,11]$. With respect to games in particular, player engagement stems from and unfolds through interactions between player and game.

Digital games can be regarded as systems composed of interrelated and interoperating elements, within which players carry out organised processes of gameplay activities in the pursuit of game goals [12,13]. Fulfilment of game objectives requires players to achieve specific game state changes. For this, players engage in gameplay activities to interact with one another and/or other interactive gameplay tokens: digital objects and entities, user-interface elements and physical input devices [12,14].

Gameplay activities develop through iterative cycles involving (re)definition of objectives, planning, action and evaluation of outcomes, based on just-in-time feedback provided by the game [15]. It is through these cycles that, if properly supported and motivated by the game, players think, feel and do, wholly engaging in gameplay dynamics.

Players' interactions within and progression through gameplay activities are defined by gameplay mechanics, i.e. systems of rules designed to: afford and constrain player actions $[12,14,16]$; determine the development of non-playercontrolled game events $[12,13]$ and regulate game state changes consequent to player action or non-player-controlled events $[12,16]$. Gameplay mechanics define functional 
interrelations and interoperations between gameplay tokens, thus determining which gameplay actions players can carry out, under what conditions, how they are carried out and with what consequences $[12,14]$. Even though all the elements of a game system contribute to defining players' willingness to play a game, gameplay activities and the underpinning mechanics are essential in triggering and sustaining players' engagement $[12,17]$.

Boyle et al. [18] suggest that most studies of player engagement in games are mainly focussed on subjective experience and motives to play. Research concerning subjective experience studies engagement in relation to the subjective psychophysical and functional state of the player [18], through measurable constructs such as flow [19], immersion [20], and enjoyment [21]. Even though the subjective experience is key in determining the appeal of a game, different constructs emphasise different aspects of the player experience, and there is no consensus regarding how to best characterise players' subjective experience [18]. Use of subjective experience alone may also add the risk of overgeneralisation.

Research on motives explores factors that determine players' motivation to engage in game play [18]. This perspective leverages theoretical frameworks such as the Uses and Gratification Theory (UGT) [22] and the SelfDetermination Theory (SDT) [23] in order to study game features that can fulfil basic player needs and preferences e.g., $[24,25]$.

Motivation-centred game research is mostly focussed on elements implicit in games [18]. Game play, however, can be both intrinsically and extrinsically motivated, like any other activity. Ryan and Deci indicate that intrinsically motivated activities are done by free choice because they are inherently satisfying (e.g., playing a game for fun), whereas extrinsically motivated activities are driven by the pursuit of separable outcomes, external to the activity itself (e.g., going to a party because of social pressures). Extrinsically motivated activities are thus instrumental to fulfil objectives which may be imposed (e.g., through coercion), or autonomously chosen to some degree by the subject engaged in the activity (e.g., playing a game in order to improve one's health). Research has shown that intrinsically motivated activities foster confidence, excitement and interest, leading to enhanced performance, persistence, creativity, heightened vitality, selfesteem and general well-being [23]. Extrinsic motivations can be integrated with intrinsic motivations potentiating these benefits, provided that people internalise and assimilate the norms and values which define extrinsic motivations and regulate behaviours accordingly, thus transforming externallyregulated activities into self-regulated ones [23].

\section{METHOD}

For the purpose of this study, we conducted a comparative content analysis of the selected cognitive training games. We examined the games adopting a motivation-centred approach informed by SDT which suggests that engaging activities should satisfy basic needs of: competence (effectiveness in interaction with the environment); autonomy (psychological freedom and choice possibilities within activities); relatedness (development of meaningful relationships with others) [23]. Consequently, we studied gameplay activities to identify, classify and analyse mechanics related to these needs, which therefore have potential to impact on player motivation and engagement. Accordingly, we focussed on mechanics key to interacting with the game environment and progression within the games, because of their importance in developing, testing and rewarding players' competence, and providing them with choice and volition possibilities. We also focussed on contextualisation mechanics because of their importance to frame and define meanings of interactions and progression, and to motivate and justify possibilities for social interactions.

The descriptive analysis resulting from this process was then used to compare and contrast the two games studied, in order to identify and discuss engagement potentialities/risks in a health game vs. leisure game, and health game vs. expected engagement requirements.

\section{DESCRIPTION OF GAMES}

In this section, both games chosen for analysis are introduced. Detailed aspects of the games mechanics are then described and analysed in a later section.

\section{A. Protect Brain Training Study}

The long-term Protect research programme (protectstudy.org.uk) [8] includes a presently ongoing 1 year Brain Training Study (BTS) based on the earlier 6 month study described by Corbett et al. [1]. Eligibility of both trials is adults 50 or over residing in the UK and excluding a diagnosis of dementia.

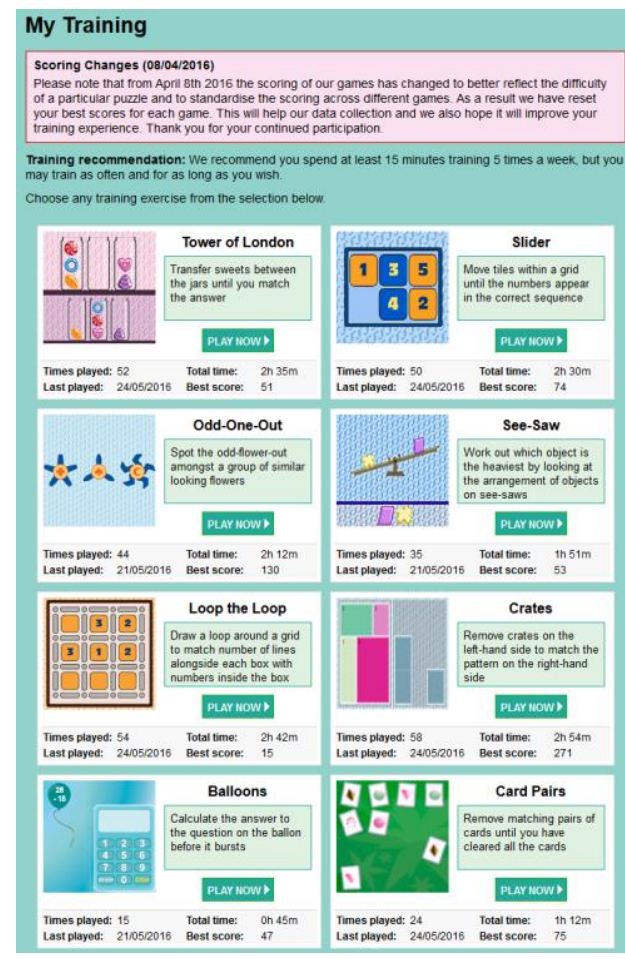

Fig. 1. Protect BTS summary screen on a enrolled player's laptop screen (screen capture by enrolled participant). 
The explicit aim of the present BTS is to see whether it results in any changes or improvements in cognition (which would be expected based on the previous trial), when brain training is used long-term. This study is also looking at whether brain training is engaging enough for people to adhere to it (we can note that a change in the new trial is the recommended number of weekly plays was increased from 3 to 5).

The Protect BTS deploys a set of visual mini-games (with basic accompanying sounds, that can be optionally turned on/off) that run in a PC web-browser (See Fig. 1). Games are selected and played with a mouse (not touch enabled) by means of single button point-and-click. There is no overarching narrative for the games except for their being part of the Protect study. Training includes 8 mini-games in four categories. There are 3 planning and 3 reasoning games which are based on tasks in a previous internet "reasoning and problem solving brain training" package (ReaCT) and two more games were added a little later which have similarity with one maths and one memory tasks in general cognitive training (GCT). ReaCT and GCT are both described in [1].

The reasoning tasks include: See-Saw, picking the heaviest object type by deducing weight relationships of objects placed on a given set of see-saws which are shown to be weighted either left, right or perfectly balanced; Odd-One-Out/Flower finder, selecting one unpaired flower from an odd number of flowers which vary either in petal colour, inner colour, petal, shape, inner shape, or petal number; Crates, removing coloured Tetris-style shapes from a pile, the remaining shapes which then fall under gravity, to match a goal 'silhouette' (single colour) arrangement at the side.

The planning tasks include: Loop the Loop, drawing a closed line on a grid, subject to constraints about the number of edges of each grid-square that can be used; Tower of London, rearranging a set of 5 different objects inside 3 jars (which hold a maximum of 3 objects each) to match a goal arrangement underneath, by moving one object at a time (one click to remove it, another to replace it in a different jar); Slider, shifting numbered tiles in a grid (initially $2 \times 3$ ) to put them in numerical order, clicking any tile that is next to the single unoccupied square.

A later-added maths game is Balloons. Party balloons floating up the screen are popped by working out the correct sum that is written on them (either addition, subtraction, multiplication or division) using an onscreen calculator with mouse (or optionally, keyboard) input. The last game, also added later, is Card Pairs, a 'concentration' memory game (matching pairs to be picked from a set of several pairs of cards that are first shown all together, then turned over).

Each mini-game in Protect BTS is timed to be played for 3 minutes. Trial participants are asked to play games from the set of mini-games for a total period of at least 15 minutes each session, 5 times a week without constraint on which games are played. Outcomes measures in the BTS with clinical purpose include self- and informant-reported Activities of Daily Living ratings and performance on a battery of cognitive tests (different from the training games) at the start of the trial, after 6 weeks, and at the end of the trial (one year).

\section{B. Big Brain Academy}

Big Brain Academy (BBA) is a leisure version of brain training (no claim is made about real-world efficacy) for adults or children that was initially deployed on the Nintendo DS mobile game platform and then as a 'sequel' on the Nintendo Wii television games console platform. In this paper we describe only BBA for Wii (also named BBA: Wii Degree in the non-PAL TV region) [9] which is played on the Wii games console connected to a television, and uses a hand-held Wii Remote as a point-and-click device similar in effect to a single button computer mouse but which is waved around at a distance from a sensor bar placed on top of the TV screen and which includes an audio source (in addition to that of the TV). Other buttons are present on the Wii remote but these are not used during game play.

The setting and overarching narrative for the game is a school where players are enrolled as students who train and take tests to improve their 'brain weight', whose endeavours are led by a teacher avatar, headmaster Professor Lobe (see Fig. 2).

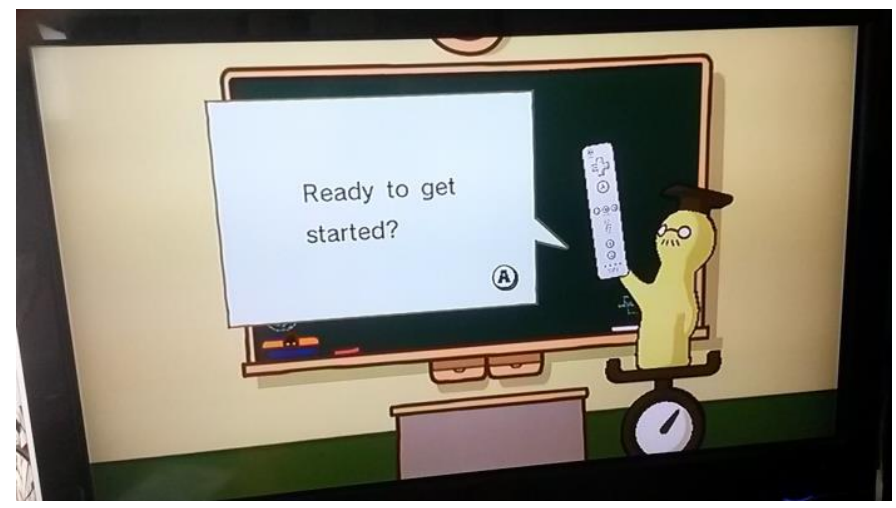

Fig. 2. BBA for Wii teacher avatar on a enrolled player's TV screen, introducing game and demonstrating Wii Remote (photograph by MC).

BBA comprises of a set of 15 mini-games, 3 in each of 5 categories: Identify; Memorise; Analyse (reasoning); Compute (maths questions); Visualise (including visuo-spatial). The games are mostly visual with a few examples of auditory sequencing and accompanying sound effects used throughout. Test mode uses the same games as the Practice training. The categories are illustrated in Fig. 3 and an example of one BBA mini-game is shown in Fig. 4.

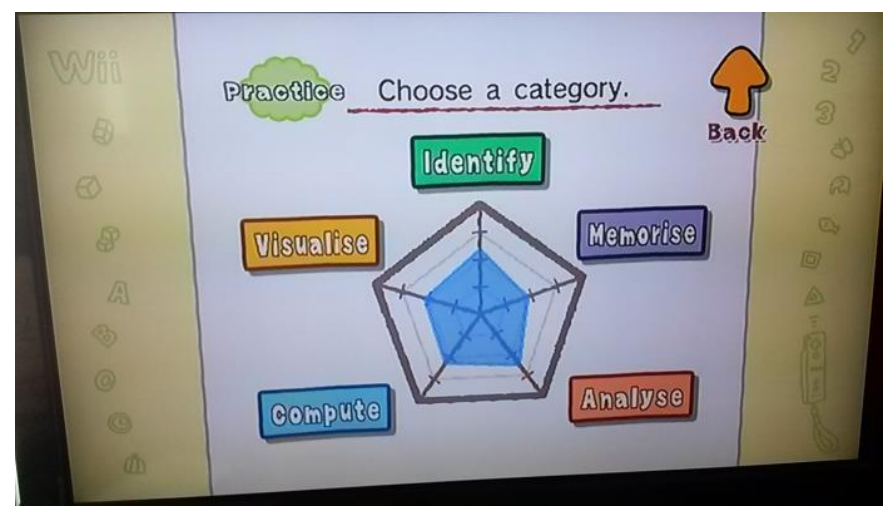

Fig. 3. BBA for Wii categories (photograph by MC). 


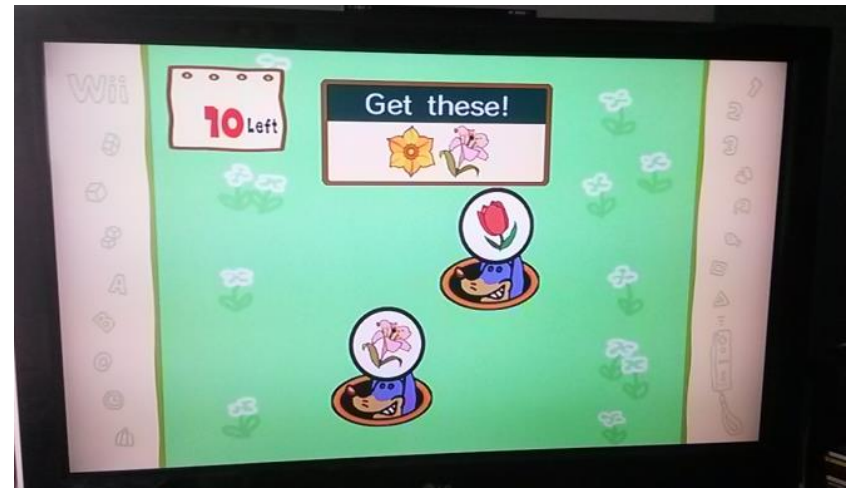

Fig. 4. BBA for Wii example game Whack Match (photograph by MC).

The brain weight metaphor is clearly seen in the graphical/animated display of a brain and scales (Fig. 2 and Fig. 3).

The mini-games within the five categories are now described.

The Identify games include: Whack Match, a 'splat the rat' type game with a set of objects to obtain by hitting them with a hammer whilst avoiding objects not in the set, prompted by the words 'Get these!' (as seen in Fig. 4); Fast Focus, selecting the word to match a gradually appearing picture prompted by the question 'What is This?'; Species Spotlight, counting a scene of three different species of animals partially lit by a moving spotlight prompted by the question 'What are there more of?'

Memorise games include: Covered Cages, a variant of 'cups and balls', where occupied and empty birdcages are swapped around, after which the player has to click only on the ones with birds inside, prompted by the words 'Keep track of the birds!' and subsequent question 'Where are they?'; Face Case, choosing heads of characters that appear in and disappear from a scene (not all at the same time) from a lineup of similar faces prompted by the words 'Watch closely!' and question 'Who appeared?'; Reverse Retention, reproducing the reverse sequence of objects/faces/numbers/ sol-fa (with sounds) presented in order prompted by the words 'Memorize this!' and 'Repeat in reverse!'

Analyse games include: Match Blast, a similar game to Crates above but with single colour for the blocks, prompted by words 'Copy the top pattern!'; Speed Sorting, selecting from 4 photographs the one(s) that best one to accompany the information given above e.g., Has Six Legs!, Bird!, Fastest!; Block Spot, matching the given rotating object to the correct one of a set of 3D rotating objects (similar to Rubik cubes with pieces missing), prompted by the question 'Which is the same?'

Compute games include: Balloon Burst, select numbers on a set of different-sized balloons in reverse order, prompted by the words 'Pop from lowest to highest!'; Mallet Math, hitting away blocks so the remaining ones add to the given total, prompted by the words 'Sum up!'; Color Count, spotting the colour of the largest number of either red or blue balls that have gone into a basket one-by-one, prompted by the words 'Keep track of the balls!' and question 'Which scored more?'
Visualise games include: Art Parts, completing a graphical picture with objects in a scene compared to a goal scene; Train Turn, selecting the correct pieces to complete a train track in different orientations, prompted by the words 'Get the train to the exit!'; Odd One Out, selecting the odd one out from four animated scenes prompted by the question 'Which is Different?'

The games can be played by a single player or as variants of these in multiplayer competitive and co-operative modes Mind Sprint, Mental Marathon and Brain Quiz, which are all designed for either up to 4 players or 8 players. In Mind Sprint either one relay team of 4 plays against a student record, or two relay teams of 4 play each other (using 2 Wii Remotes). Players may choose the desired categories and difficulty levels or else the game can automatically balance the difficulty according to each player's student record. In Mental Marathon, up to 8 players play a timed series of games against each other and in Brain Quiz up to 8 players and 4 teams play 20 games (the 15 practice games, plus 5 extra games not described in this paper) selected by turning over a panel to reveal it and its difficulty level.

The Test mode, which is compulsory when the player first enrols, and then optional afterwards, presents the games in turn to calculate an overall 'brain weight' which is show at the end of the test as an animated brain on a set of scales. The scores in each category of test are presented as a Brain Graph (spider/radar chart) to show the player's ability in each area. The test score and grade is added to the student record (see later for details). Student records can be shared with other players over the internet.

\section{ANALYSIS}

The following section concentrates mainly on the training aspects of the games as this is comparable between Protect BTS and BBA for Wii but also refers more briefly to the testing and multiplayer games features of BBA Wii. A following section after analysis of mechanics will consider additional aspects of the games that contribute to engagement, including the narrative, social and discovery aspects of game play in BBA for Wii. Keyboard entry is an option for entering numbers in one maths game, Balloons.

\section{A. Interaction mechanics}

\section{Types of gameplay actions allowed}

Protect BTS: Point and click at objects which move, disappear or are selected, during each round of mini-game play. Clicks are also used to start the game, restart a round, or abandon the game early.

BBA for Wii: Mainly point-and-click at objects either during each round, or at the end of the round e.g. in the case of Color Count, or both as in the memory games Face Case and Reverse Retention. Clicking on objects selects them, moves them or makes them disappear. In Art Parts the players drags and drops foreground objects on to the background scene of a picture. Clicks are also used to select the game to play and to select difficulty level. 


\section{Rules of interaction}

Protect BTS: Some of the mini-games involve a single mouse click per round e.g., in See-saw the object deemed heaviest is selected from the possible set of objects shown in a horizontal list under the see-saws and in Odd-One-Out, the flower deemed odd (not in a pair with any other flower) is clicked on directly. Crates also involves direct selection on screen to delete shapes. In others of the mini-games multiple clicks are/may be required e.g. Balloons where 1 to 3 digits are clicked followed by Enter (or are input via the computer keyboard) and in Loop the Loop where several edge sections of the grid must be clicked to form the loop before clicking Submit. In Tower of London, the top sweet in a jar is first moved up out of the jar by clicking its jar and then the preferred destination jar is selected by a second click which is allowed so long as the jar is not full. In Card Pairs, two identical cards must be turned one after the other before they will disappear.

BBA for Wii: Some of the mini-games involve a single mouse click per round and others require multiple clicks. Some involve selecting from a set of objects next to the scene, others directly selecting the object. In the case of Art Parts the article is dragged after which a click is used to drop the object one at a time, and in Train Turn a click is used to select, in turn, each piece of track to best suit the part of the scene showing a question mark. In Whack Match the objects appear and disappear quickly and so require good attention and reaction time. Most the games involve time-limited tasks.

\section{Game feedback to facilitate learning of rules of interaction}

Protect BTS: On the start screen, animation is used to demonstrate aspects of game play, with text-box explanations to accompany segments of the animation. Objects move or are highlighted when clicked on, or do not move if the play is illegal. In one game, Loop the Loop, a second chance is allowed after clicking Submit and the incorrect edges are highlighted in red colour.

BBA for Wii: As described above, words and questions are visible during play of each game which are linked to the required action. Some game have prompts with words both before and after the stimuli are presented e.g. in Memorise category games (see above).

\section{B. Progression mechanics}

\section{Mechanics regulating access to game}

Protect BTS: Any of the 8 mini-games can be freely chosen and are first shown on a single 'summary' screen which includes a brief description of each game. The player clicks on the game they wish to play and its start screen is shown as a window with a text explanation of its rules on the left and the gameplay animation is shown on the right. The player then may press Start or return to the summary screen. Every game has a clock counting down from 3 minutes (with ticking audio) and starts with an extra 3 second countdown $(3,2,1$, Go) on-screen and finishes with a 10 second countdown on the clock where the digits go red during which time the ticking sound is stronger. The player may stop the mini-game by clicking ' $x$ ' on the game window before the three minutes are up but the session count is not incremented (although the time played is added).

BBA for Wii: In Practice mode any of the mini-games can be freely chosen and the player first chooses one of the 5 minigame categories and then 3 difficulty levels are presented: Easy, Medium or Hard which can also be freely chosen from. A fourth hidden level Expert is revealed/unlocked when gold is achieved in all lower levels.

\section{Objectives of the game (completion conditions GCC; stage completion conditions SCC)}

Protect BTS: GCC - Each game is played repeatedly until 3 minutes has elapsed. SCC - a round (stage) is completed when the puzzle is either successfully solved or a click/move limit is reached (in some of the mini-games), or if the 3 minutes are up.

BBA for Wii: GCC - In Practice mode, each mini-game has 10 rounds ('practice problems'). SCC - A round is completed either when a puzzle is solved or an incorrect solution has been clicked on, or the puzzle times out.

\section{Game feedback to communicate objectives}

Protect BTS: The objectives are presented on the start screen and may also be viewed during the game by clicking '?' although the clock continues to count down.

BBA for Wii: The objectives are shown using textual commands or questions and these are shown above the mini game graphics (actual text is detailed above in the mini-game descriptions).

\section{Articulation of progression (organisation of game stages)}

Protect BTS: The game is organised into rounds which are repeated continuously over the 3 minutes with more obvious incremental difficulty in some of the games e.g., more pairs to process in Card Pairs as the game progresses. There is no time limit to complete a round but there is a move limit in some games whereby a round is ended if too many moves are made without successful completion. By clicking on a reset icon, the player can choose to restart a round to try it again from the start without scoring penalty (although time is lost). During some of the mini-games the puzzle difficulty may stepup or step-down in a more obvious manner e.g., from $2 \times 3$ to $3 \times 3$ grid in Slider and this is controlled by the game based on the player's performance during the game. A new difficulty step is maintained from the start of the next game.

BBA for Wii: In each of the mini-games, 10 rounds are played. A round time-out if the player is too slow. Difficulty level is framed for each of the mini-game start screens and increases with level (Easy, Medium or Hard). There is also some incremental difficulty.

\section{Rules of progression within game}

Protect BTS: Difficulty level within game is stepped-up if the player has been playing quickly and accurately. If a player subsequently plays poorly at a higher step level the difficulty can step-down. Rules for continuous incremental difficulty during the games are not explicit. 
BA for Wii: In Practice mode, difficulty level is framed within the mini-game and increases with level, and there is also a continuous difficulty increment over time within-game in some of the games e.g., Color Count where the number of balls shown at one time in a round gradually increases. The player is free to choose a more challenging level at the start of the mini-game. In Test mode, difficulty is matched to Practice mode performance.

\section{Game feedback to facilitate learning of rules of progression}

Protect BTS: Progression rules are not explained and are therefore implicit. Score is increased more rapidly if the player is playing quickly and accurately and this may result in stepping up of difficulty. Conversely, errors in rounds result in penalties (negative scoring) and a poor score during play may be more obviously accompanied by a stepping-down.

BBA for Wii: In Practice mode, difficulty level is freely chosen by the player for each mini-game play. The player is not restricted in choice of level (Easy, Medium or Hard). Within-game progression is judged implicitly from the perceived difficulty.

\section{Game feedback to acknowledge progression (completion of game; completion of stage)}

Protect BTS: Game Over screens appear at the end of each mini-game, and some games may add the words 'You Did Well' which appears to be based on absolute score achieved. Progression to a higher difficulty step is not acknowledged. After completion of game the player may Exit and revert to the summary screen or Replay.

BBA for Wii: The number of rounds left is displayed. The Wii Remote also speaks the number of rounds that are left. After the game, the player goes to a classroom screen where the results are given by the teacher avatar.

\section{Mechanics designed to support progression}

Protect BTS: Depending on the game, stepping-up may involve presenting more stimuli graphics to process (which appear smaller in size to fit the window) e.g., See-saw, OneOne-Out or a larger grid to solve e.g., Loop the Loop, Slider. In See-saw, difficulty is stepped-up by having a greater selection of objects to process and also introducing more confounding objects that are the same on both sides of the seesaw, as well as an increase in the number of see-saws to process. Stepping-up in Tower of London involves an increase in the number of clicks required to rearrange the objects in the jars to achieve the goal arrangement. Similarly, Slider requires a greater number of moves to put the digits in numerical order as difficulty increases (before the grid size is increased).

BBA for Wii: Either single or multiple clicks are required to complete a round. In some games the player must wait until the end of the round to make their selection.

\section{Mechanics designed to challenge players}

Protect BTS: Every mini-game has a time limit of 3 minutes. A score is awarded for each round, presented at its end, for successful completion. In most games, a penalty of a similar size is awarded for incorrect solution or a time-out. A higher score at end of game is therefore achieved by accurately completing more rounds. In some games the score per round is increased incrementally as it progresses during the 3 minutes. However, since difficulty is also stepped it becomes more difficult to complete a round accurately and quickly because it is cognitively more demanding and some of them require more clicks to complete the puzzle. This in turn affects the overall score achievable. Stepping such as increase in grid size of Loop the Loop, makes it more difficult to improve on the high score.

BBA for Wii: In Practice mode, although the number of plays is the same (10 in total) the game play is cognitively more demanding according to difficulty level. Some of the games can be speeded up to make them more challenging (with an accompanying increase in score e.g., Color Count). Other examples of challenge mechanics include: more objects to process, smaller degree of difference between scenes or objects within scene, more complex information given, greater digit span (including negative numbers). Therefore, more skill and ability is required to complete a high proportion of the 10 rounds.

\section{Mechanics designed to reward players}

Protect BTS: The high score is presented on the summary screen (although not on the start screen, nor during play, nor at the end of a game). Total number of plays, total time played and date of last play are also shown for each mini-game. During play, a green tick is shown for each successful round completed, and a red cross for an unsuccessful one (with accompanying sounds).

BBA for Wii: In most games, faster play is rewarded. During play, green ticks and red crosses are used after each round, similar to Protect BTS. One type of reward at end of game is either praise for success or admonishment and encouragement (to do better next time) from the teacher avatar (as text). The teacher comments on the brain weight achieved e.g. 'A good size, [player_name]. I hope it's a sign of things to come' or 'A bit light, isn't it? I'm sure you'll add more soon [player_name]!' and a medal is awarded if the player exceeds a particular threshold brain weight. There are three main medals, bronze ( $100 \mathrm{~g}$ or more), silver $(200 \mathrm{~g}$ or more) or gold (300g or more) plus a surprise platinum medal for exceptional play (400g or more). Medals are awarded with accompanying praise (text), an audio fanfare and coloured ribbons \& confetti on a stage with sound effects of other students babbling in the virtual classroom.

Student name with score achieved is added to a player ranking if the score in the mini-game is in the top ten for that difficulty level. The ranking screen displays a champion's crown and laurels for top scores, as shown in Fig. 5, and music is played that is appropriate to the achievement.

\section{Mechanics designed to encourage players}

Protect BTS: The high score for each mini game is presented on the summary screen although the act of beating the high score is not made explicit i.e. the player must remember the previous high score and see if it has changed on the summary screen. 


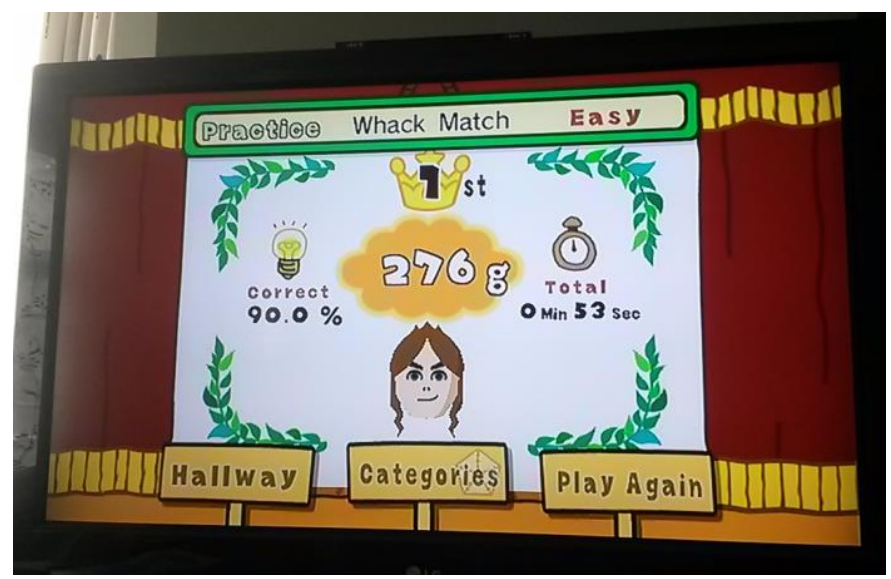

Fig. 5. BBA for Wii ranking on enrolled player's TV (photograph by MC).

An additional screen is shown after login which contains a summary of the entire play record since enrolment on the BTS. This is presented as Exercises Completed, Sessions and Total Time (hh:mm) for the current calendar week (Sunday to Monday), the current calendar month, the calendar year, and a total (which allows for annual play across year boundaries). Sessions are continuous plays (most likely determined by browser session) and Exercises completed are the number of mini-games played.

BBA for Wii: At the end of play of each mini-game, the player's individual highest brain weight and medal type are shown on the same screen for all of the three difficulty levels (included those levels not yet attempted) such that the player is implicitly encouraged to try higher difficulty levels by showing them alongside the individual best medals and brain weight scores already achieved. In Practice mode, at the start of each play, the player is asked by a voice from the TV if they are "Ready to begin/go" and "All warmed up?". The Wii Remote also speaks to the player at the start of each round and during the round tells them how many rounds are still to be completed e.g., "5 to go". It speaks if the player is on track to beat their record high score and other speech is used such as "Relax" if they fail a round. An indication of contribution to brain weight is shown at the end of each round by showing a brain of appropriate size and accompanying words such as 'Great!' or 'Super!'. At the end of the game, both the teacher avatar text and speech from the Wii Remote add words of encouragement to improve and to play regularly. Beating the record and, on repeat plays, an increase in score is acknowledged. If a medal is awarded the player is reminded of the goal threshold that has been passed for that medal and also the target for the one above it e.g., 'Now aim for $300 \mathrm{~g}$ of mass. That will put you in an elite class!'. In Test mode, the student is presented with an overall brain weight, a grade A, B-, C+ etc. and the 'Brain Graph' of overall performance in the 5 categories and a description of a vocation ('type of mind') to match the shape of the spider chart e.g. historian.

\section{Summary of game mechanics}

A structured summary of the game mechanics from the previous sub-sections and with the addition of a contextualisation category from the description section, is shown in Table 1.

TABLE I. SUMMARY OF GAME MECHANICS

\begin{tabular}{|c|c|c|c|}
\hline & \multicolumn{3}{|c|}{ Game mechanics } \\
\hline & $\begin{array}{c}\text { Description } \\
\text { of } \\
\text { mechanics }\end{array}$ & Protect BTS & BBA for Wii \\
\hline \multirow[t]{6}{*}{ Interaction } & $\begin{array}{l}\text { Device \& } \\
\text { operation }\end{array}$ & $\begin{array}{l}\text { PC web browser, } \\
\text { mouse point-and } \\
\text { click (keyboard } \\
\text { option in one game) }\end{array}$ & $\begin{array}{l}\text { TV games console, } \\
\text { Wii Remote point } \\
\text { and click (drag and } \\
\text { drop in one game) }\end{array}$ \\
\hline & $\begin{array}{l}\text { Interaction } \\
\text { requirements }\end{array}$ & Accuracy & $\begin{array}{c}\text { Accuracy, reaction } \\
\text { time }\end{array}$ \\
\hline & $\begin{array}{l}\text { Media/ } \\
\text { Communi- } \\
\text { cation }\end{array}$ & $\begin{array}{l}\text { Colour graphics, } \\
\text { feedback sounds, }\end{array}$ & $\begin{array}{c}\text { Colour graphics, } \\
\text { photographs, } \\
\text { animation, feedback } \\
\text { sounds, speech }\end{array}$ \\
\hline & Content & $\begin{array}{l}\text { Select, move, make } \\
\text { game objects } \\
\text { disappear }\end{array}$ & $\begin{array}{l}\text { Select, move, make } \\
\text { game objects } \\
\text { disappear }\end{array}$ \\
\hline & GCC & $\begin{array}{c}\text { Fixed overall time } \\
\text { limit }\end{array}$ & $\begin{array}{l}\text { Fixed number of } \\
\text { rounds }\end{array}$ \\
\hline & $\mathrm{SCC}$ & $\begin{array}{l}\text { Solve puzzle or } \\
\text { reach click/move } \\
\text { limit }\end{array}$ & $\begin{array}{l}\text { Solve puzzle, time } \\
\text { out, or make error }\end{array}$ \\
\hline \multirow[t]{4}{*}{ Progression } & Challenge & Stepping & $\begin{array}{l}\text { Distinct difficulty } \\
\text { levels, Stepping }\end{array}$ \\
\hline & Rewards & $\begin{array}{l}\text { Medals, grading, } \\
\text { highscore leader } \\
\text { board, unlocking } \\
\text { features, discovery }\end{array}$ & Individual highscore \\
\hline & $\begin{array}{l}\text { Encourage } \\
\text { ment }\end{array}$ & $\begin{array}{c}\text { Summary record of } \\
\text { total game play } \\
\text { (exercises, sessions, } \\
\text { time) }\end{array}$ & $\begin{array}{l}\text { Before play, in } \\
\text { round \& } \\
\text { Post-game }\end{array}$ \\
\hline & $\begin{array}{l}\text { Media/ } \\
\text { communi- } \\
\text { cation }\end{array}$ & $\begin{array}{l}\text { Textual feedback, } \\
\text { animation, rules of } \\
\text { game explained (but } \\
\text { not scoring or } \\
\text { progression) }\end{array}$ & $\begin{array}{l}\text { Textual, graphical, } \\
\text { sound and musical } \\
\text { feedback, rules } \\
\text { explained }\end{array}$ \\
\hline \multirow[t]{4}{*}{$\begin{array}{l}\text { Contextual- } \\
\text { isation }\end{array}$} & Narrative & Health focus & $\begin{array}{l}\text { Edutainment focus } \\
\text { with school setting, } \\
\text { and student } \\
\text { enrolment and } \\
\text { record. Brain weight } \\
\text { and scales metaphor }\end{array}$ \\
\hline & $\begin{array}{l}\text { Character } \\
\text { customis- } \\
\text { ation }\end{array}$ & N/A & Mii \\
\hline & Media & N/A & $\begin{array}{l}\text { Music \& classroom } \\
\text { sound effects }\end{array}$ \\
\hline & Social & N/A & $\begin{array}{l}\text { Multi-player games, } \\
\text { sharing of student } \\
\text { record }\end{array}$ \\
\hline
\end{tabular}

\section{DISCUSSION AND CONCLUSIONS}

The aim of this exploratory study is not to judge relative merit from mechanics alone. However, the side-by-side comparison shows that there are some clear differences in use of mechanics in these health (non-leisure) and leisure cases. In particular, the leisure game uses a greater number of mechanics, a greater variety of media, and has a richer ingame context. A larger number of interaction and progression mechanics could foster players' control and mastery development, hence promoting sense of autonomy and competence [23, 24]. Richer and deeper contextualisation mechanics could benefit the personalisation of the play 
experience, enhancing sense of presence and immersion [24]. The social mechanics in the leisure game could satisfy players' socialisation needs, promoting sense of relatedness [23]. Taking the above into account, the enhanced richness of the leisure game could make it more intrinsically motivating. On the other hand, the health goal associated with the Protect study could represent a positive extrinsic motivation likely to be internalised, integrated with intrinsic motivations presented by the game itself, and the altruistic motivation to contribute to research through engaging in a trial. There are also some similarities, such as the use of mouse-like point-and-click whereas other options such as touch are not available. Interaction affordances facilitate players' control and support mastery development, hence contributing to intrinsic motivation in both games.

This study could be furthered using a more detailed description of game mechanics as a structured framework to identify elements promoting engagement, and then test these through user studies and expert reviews eliciting opinions and preferences of users, game designers and healthcare experts. This would also involve determining which elements are key to triggering and sustaining player engagement in ways essential for the success of health (non-leisure) cognitive training, and which elements are beyond the essential i.e., those that have potential to further enhance the experience/pleasure of cognitive training. More specific guiding questions for the next step in our research include: which activities/mechanics afford or hamper engagement and intrinsic motivations, and which facilitate integration and internalisation of extrinsic motivations? It will also be necessary to understand more fully the needs of health and cognitive psychology professionals who are (or should) be involved in game specifications. In particular, being at a distance in this analysis, we have not explored such requirements in the Protect BTS. However, we have noted elsewhere that there are constraints in the deployment of certain content into cognitive tests e.g., those that may bias perception [26]. Use of tests (exams) that are different from training tasks may mitigate against a near transfer effect. Literacy and numeracy are also important aspects of study designs aimed at wide participation (and large sample size).

Finally, another step in the research would be to investigate appropriateness of game activities and mechanics reflecting on the effect on motivation for people with particular cognitive impairments.

\section{REFERENCES}

[1] A. Corbett, A. Owen, A. Hampshire, J. Grahn, R. Stenton, S. Dajani, et al., "The Effect of an Online Cognitive Training Package in Healthy Older Adults: An Online Randomized Controlled Trial," J Am Med Dir Assoc, vol. 16, pp. 990-7, Nov 12015.

[2] E. M. Zelinski and R. Reyes, "Cognitive benefits of computer games for older adults," Gerontechnology, vol. 8, pp. 220-235, Fall 2009.

[3] J. A. Garcia-Casal, A. Loizeau, E. Csipke, M. Franco-Martin, M. V. Perea-Bartolome, and M. Orrell, "Computer-based cognitive interventions for people living with dementia: a systematic literature review and meta-analysis," Aging Ment Health, pp. 1-14, Jan 252016.

[4] S. McCallum and C. Boletsis, "Dementia Games: A Literature Review of Dementia-Related Serious Games," in Serious Games Development and Applications: 4th International Conference, SGDA 2013, Trondheim, Norway, September 25-27, 2013. Proceedings, M. Ma, M.
F. Oliveira, S. Petersen, and J. B. Hauge, Eds., ed Berlin, Heidelberg: Springer Berlin Heidelberg, 2013, pp. 15-27.

[5] P. H. Robert, A. Konig, H. Amieva, S. Andrieu, F. Bremond, R. Bullock, et al., "Recommendations for the use of Serious Games in people with Alzheimer's Disease, related disorders and frailty," Front Aging Neurosci, vol. 6, p. 54, 2014.

[6] T. T. Cota, L. Ishitani, and N. Vieira, "Mobile game design for the elderly: A study with focus on the motivation to play," Computers in Human Behavior, vol. 51, pp. 96-105, Oct 2015.

[7] A. Lampit, H. Hallock, and M. Valenzuela, "Computerized cognitive training in cognitively healthy older adults: a systematic review and meta-analysis of effect modifiers," PLoS Med, vol. 11, p. e1001756, Nov 2014.

[8] KCL. (2016, 13/05/2016). PROTECT Study Available: http://www.protectstudy.org.uk/

[9] Nintendo. (2016, 13/05/2016). Big Brain Academy for Wii. Available: https://www.nintendo.co.uk/Games/Wii/Big-Brain-Academy-for-Wii280616.html

[10] J. A. Fredricks, P. C. Blumenfeld, and A. H. Paris, "School engagement: Potential of the concept, state of the evidence," Review of Educational Research, vol. 74, pp. 59-109, Spr 2004.

[11] W. B. Schaufeli, "What is engagement?," in Employee Engagement in Theory and Practice, C. Truss, R. Delbridge, K. Alfes, A. Shantz, and E. Soane, Eds., ed London: Routledge, 2013, pp. 15-35.

[12] C. Fabricatore, "Gameplay and game mechanics design: a key to quality in videogames," Proceedings of the OECD-CERI Expert Meeting on Videogames and Education, pp. 1-18, 2007.

[13] C. Fabricatore and X. Lopez, "A Model to Identify Affordances for Game-Based Sustainability Learning," Proceedings of the 8th European Conference on Games Based Learning (ECGBL 2014), vol. 1 \& 2, pp. 99-109, 2014.

[14] J. Schell, The Art of Game Design: a Book of Lenses. Burlington, MA: Morgan Kaufmann, 2008.

[15] C. Fabricatore and X. López. (2012, 08/06/2016). Sustainability Learning through Gaming: An Exploratory Study. Electronic Journal of E-Learning (EJEL) 10(2), 209-222 Available: http://www.ejel.org/issue/download.html?idArticle=194

[16] K. Salen and E. Zimmerman, Rules of Play: Game Design Fundamentals. Cambridge, MA: MIT Press, 2003.

[17] C. Fabricatore, M. Nussbaum, and R. Rosas, "Playability in action videogames: A qualitative design model," Human-Computer Interaction, vol. 17, pp. 311-368, 2002.

[18] E. A. Boyle, T. M. Connolly, T. Hainey, and J. M. Boyle, "Engagement in digital entertainment games: A systematic review," Computers in Human Behavior, vol. 28, pp. 771-780, May 2012.

[19] M. Csikszentmihalyi, Flow: The Psychology of Optimal Experience. London: Harper Collins, 1990.

[20] C. Jennett, A. L. Cox, P. Cairns, S. Dhoparee, A. Epps, T. Tijs, et al., "Measuring and defining the experience of immersion in games," International Journal of Human-Computer Studies, vol. 66, pp. 641661, Sep 2008.

[21] E. D. Mekler, J. A. Bopp, A. N. Tuch, and K. Opwis, "A systematic review of quantitative studies on the enjoyment of digital entertainment games," Proceedings of the 32nd annual ACM conference on Human factors in computing systems - CHI '14, pp. 927-936, 2014.

[22] T. E. Ruggiero, "Uses and gratifications theory in the 21 st century," Mass Communication \& Society, vol. 3, pp. 3-37, 2000.

[23] R. M. Ryan and E. L. Deci, "Self-determination theory and the facilitation of intrinsic motivation, social development, and well-being," American Psychologist, vol. 55, pp. 68-78, Jan 2000.

[24] R. M. Ryan, C. S. Rigby, and A. Przybylski, "The motivational pull of video games: A self-determination theory approach," Motivation and Emotion, vol. 30, pp. 347-363, Dec 2006.

[25] J. L. Sherry, K. Lucas, B. S. Greenberg, and K. Lachlan, "Video game uses and gratifications as predictors of use and game preference," in Playing Video Games: Motives, Responses, and Consequences, P. B. Vorderer, J. , Ed., ed Hillsdale, NJ: Lawrence Erlbaum Associates, 2006, pp. 248-262.

[26] M. P. Craven and M. J. Groom, "Computer Games for User Engagement in Attention Deficit Hyperactivity Disorder (ADHD) Monitoring and Therapy," in 2015 International Conference on Interactive Technologies and Games, Nottingham, UK, 2015, pp. 34-40. 
